\title{
Reseńa del libro La educación transdisciplinaria
}

\author{
Book review Transdisciplinary education
}

Nicolás Gabriel Falcettoni ${ }^{\mathrm{A}}$ ORCID: 0000-0002-0265-8952

Cómo citar: Falcettoni, N. G. (2019). Reseña del libro La educación transdisciplinaria. Ciencia y Educación, 3(2), 51-52.

Doi: https://doi.org/ 10.22206/cyed.2019.v3i2.pp51-52

La educación transdisciplinaria de Nahuel Luengo y Fidel Martínez (2018) es de acceso libre a toda la comunidad y puede ser descargado desde la plataforma de la editora. Por ello, se destaca que el fin último del mismo es la divulgación científica por sobre la publicación de alcance económico. Tal y como expresa la editora, el objetivo es publicar libros digitales de acceso abierto y, a su vez, poder venderlos a un bajo costo si alguien lo desea en formato papel.

La construcción de la obra se basa en la transdisciplina y cómo se podría desde ese enfoque abordar e innovar los procesos educativos en América Latina. En efecto, desde la transdisciplinariedad los autores recuperan diversas teorías provenientes de diferentes campos científicos, con la finalidad de interrelacionarlas con experiencia y aplicaciones. De esta forma, Luengo y Martínez, estructuran el libro en dos capítulos; el primero, aborda aquellos conocimientos o sustentos teóricos indispensables para pensar en la transdisciplina; el segundo, se basa en una construcción de la educación tansdisciplinaria a partir de los estudios y la influencia de dichos conocimientos.

En el primer capítulo, denominado "Los fundamentos epistemológicos de la complejidad", se relata de manera ensayística la crisis que atraviesa el modelo económico en América Latina y el formato educativo. A su vez, se analizan las corrientes epistemológicas que han dado lugar a otros campos complejos, desarrollando minuciosamente aquellas perspectivas o dimensiones que contribuyen a la comprensión de los estudios de la complejidad. En este sentido, los autores describen las siguientes: ciencia, cosmovisión y método. En consecuencia, los epígrafes comprendidos en el primer capítulo construyen, históricamente, analizan y reflexionan aquellas dimensiones descritas anteriormente. Es decir, los autores explican los nuevos enfoques o teorías que nacen a partir de cada perspectiva; encontramos teorías como caos, sistemas complejos, topología no lineal, geometría fractal y lógica borrosa. Cada una de ellas es recuperada para explicitar quiénes fueron sus pensadores, cómo surgen las distintas ideas y qué aplicaciones poseen.

Para concluir el capítulo, los autores exponen una serie de argumentos que justifican la transdisciplinariedad en la educación y en otros ámbitos, expresando las ventajas que podría tener el trabajo transdisciplinario y los caminos necesarios para su implementación. De este modo, el primer capítulo permite un acercamiento epistemológico a un conjunto de teorías y conceptos que pueden interrelacionarse para generar una educación transdisciplinaria. En efecto, aquella persona (docente, estudiante, investigador, u otro)

A. Instituto Superior de Educación Física de General Pico, La Pampa, Argentina. Correo-e: nicofalcettoni@gmail.com 
que se encuentre con esta sección, podrá formarse una idea de lo que significa la transdisciplina.

Continuando con la lectura, en el capítulo dos, intitulado "La construcción de una educación transdisciplinaria", los autores introducen al lector en un recorrido geográfico de experiencias en la educación transdisciplinaria, es decir, desarrollan y analizan los abordajes transdisciplinarios que distintos países —en su mayoría latinoamericanos - han llevado a cabo en algunas universidades. Paralelamente, destacan qué elementos pueden contribuir a la construcción de una educación transdisciplinaria, esto es, alcanzar una integración del saber y cómo se deben analizar los actores participantes que en ella se incluyen.

Luengo y Martínez, además, colocan una lista de premisas indispensables a la hora de pensar en una educación transdisciplinaria, reflexionando sobre qué aportes podrían brindar los actores educativos y sociales. Por último, como cierre del capítulo dos, sitúan al lector en la realidad que atraviesa América Latina para socializar los trabajos y experiencias en la transdisciplina. No obstante, agregan algunas ideas estratégicas que pueden cooperar en la divulgación transdisciplinaria.

Para finalizar, el libro permite desnaturalizar y criticar aquella educación que es tratada desde los modelos tradicionales y positivistas, es decir, romper con el paradigma metódico y lineal de la enseñanza. Por este motivo, quien lea La educación transdisciplinaria podrá acceder a repensar y a cuestionar conceptos e ideas que hasta en la actualidad son reproducidos por la mayoría de los actores educativos.

\section{Referencias}

Luengo, N. A. \& Martínez A., F. (2018) La educación transdisciplinaria. Buenos Aires, Argentina: Comunidad Editora Latinoamericana. 